\title{
Ultra-Pro Hernia System for Repair of Primary Complex Inguinal Hernia: Should It Be the Technique of Choice?
}

\author{
Tamer A. El-Bakary ${ }^{*}$, Nizar M. Bouchiba ${ }^{2}$, Mohamed S. El-Akkad ${ }^{2}$, Ahmed S. El-Faki² \\ ${ }^{1}$ Department of General Surgery, Tanta University Hospital, Tanta, Egypt \\ ${ }^{2}$ Department of General Surgery, Al-Wakra Hospital, Hamad Medical Corporation, Al-Wakra, Qatar \\ Email: *telbakary@yahoo.com
}

How to cite this paper: El-Bakary, T.A., Bouchiba, N.M., El-Akkad, M.S. and ElFaki, A.S. (2017) Ultra-Pro Hernia System for Repair of Primary Complex Inguinal Hernia: Should It Be the Technique of Choice? Surgical Science, 8, 94-101. https://doi.org/10.4236/ss.2017.82012

Received: December 29, 2016

Accepted: January 23, 2017

Published: January 26, 2017

Copyright (๑) 2017 by authors and Scientific Research Publishing Inc. This work is licensed under the Creative Commons Attribution International License (CC BY 4.0).

http://creativecommons.org/licenses/by/4.0/ (c) (i) Open Access

\begin{abstract}
Purpose: The introduction of light weight three-dimension meshes into the field of inguinal hernia repair showed excellent outcomes. Ultrapro Hernia System (UHS) is one of these three-dimension meshes that allow reinforcing the pre-peritoneal space with minimal fixation. It improves the patient quality of life with rapid resumption of the daily activities. The aim of this study is to evaluate the short-term outcomes of open mesh repair of primary complex inguinal hernia using UHS mesh. Methods: Between November 2013 and November 2015, seventy five male patients with complex primary inguinal hernia were submitted to open inguinal hernia mesh repair using the UHS. Results: The mean age was 46.1 years. Thirty three patients had inguinoscrotal hernias, 14 with Nyhus type IIIA, 22 with Nyhus type IIIB, \& 6 patients had strangulated hernias. The mean operative time was 48 minutes. No operative complications were recorded. Post-operatively, the mean VAS scale on 1 day, 1 week, \& 1 month was $3.22,1.2$, \& 0.3 respectively. The mean duration of oral analgesics use was 2.1 days. None of the patients reported any chronic pain at 12 months post-operatively. Two cases of superficial wound infection were recorded that were treated by oral antibiotics. No recurrence was reported during a mean follow-up period of 26 months. Conclusion: Inguinal hernia repair using UHS is an effective technique that combines the advantages of the anterior and the pre-peritoneal approaches. It improves the patient's quality of life with minimal recurrence rates. A larger number of patients with longer follow up periods are needed to increase the validity of our results.
\end{abstract}

\section{Keywords}

Inguinal Hernia, Open Mesh Repair, Ultrapro Hernia System 


\section{Introduction}

The development of Lichtenstein tension-free polypropylene mesh hernioplasty was one of the breakthroughs in the treatment of inguinal hernia as it decreased the recurrence rates to $1 \%-2 \%$ [1]. Later on, many surgeons applied another technique where they used the posterior pre-peritoneal mesh placement method especially in the recurrent cases [2] [3].

Gilbert had developed another solution for mesh repair of inguinal hernia. His technique combined Lichtenstein repair in which the mesh was placed between the internal and external oblique muscles with the pre-peritoneal approach. $\mathrm{He}$ used the "Prolene Hernia System" which is a new devise formed of circular mesh placed in the pre-peritoneal space with a connector placed in the defect that connects the pre-peritoneal mesh with another flat mesh that covers the floor of the inguinal canal [4].

A second generation of the bilayer mesh is the Ultra-Pro Hernia System (UHS) (Johnson \& Johnson, USA) which is a partially absorbable bilayer mesh that is made of onlay and inlay patches connected by a cylindrical connector placed by the same technique described by Gilbert but it is a light-weight mesh partially made of absorbable material to reduce the post-operative chronic pain and discomfort occurring with the classic heavy weight prolene mesh [5] [6]. This study is aiming to evaluate the short-term outcomes of the open repair of complex primary inguinal hernia using UHS mesh.

\section{Patients \& Methods}

This study was carried out between November 2013 and November 2015 in Al-Wakra Hospital, Hamad Medical Corporation, Qatar. The study protocol was fully approved by the ethical committee and the Medical Research Department in Hamad Medical Corporation, Qatar. The study included 75 male patients with complex primary inguinal hernia. This includes patients with inguino-scrotal hernias; Nyhus type IIIA \& IIIB [7], \& strangulated hernia. Exclusion criteria included Nyhus type I and II patients with incomplete indirect inguinal hernia, femoral hernia (Nyhus type IIIC), recurrent inguinal hernia (Nyhus type IV), and inguinal hernia in females.

All the patients were diagnosed clinically to have inguinal hernia and an informed consent was taken from them.

Then, they were operated by open mesh repair of inguinal hernia using the Ultra-Pro Hernia System (UHS). All the patients received prophylactic antibiotic in the form of 1 gram of intravenous Cefazolin on induction of anesthesia. UHS is a 3-dimensional partially absorbable light weight mesh which is made of onlay and inlay patches connected together by cylindrical connector (Figure 1). Because it is partially absorbable, it leaves behind $65 \%$ less prolene in comparison to the old meshes [8].

The operation starts with the classic inguinal incision opening the skin, subcutaneous tissue, and the external oblique aponeurosis. Then, dissection of the 


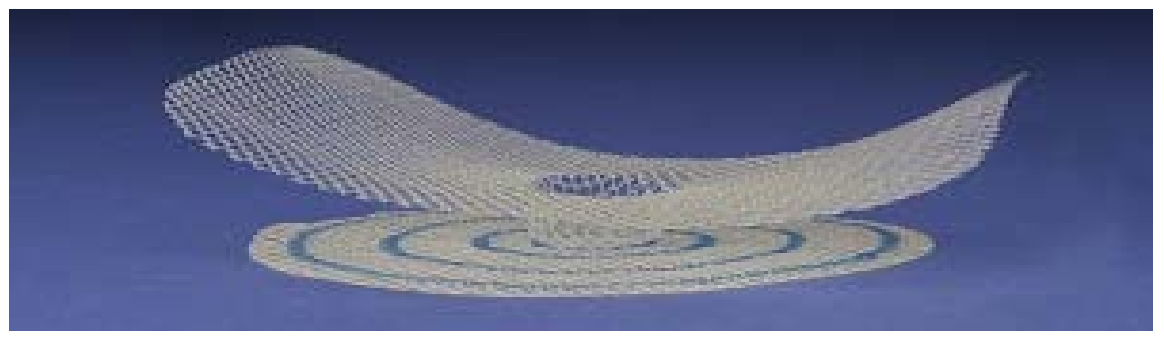

Figure 1. Ultrapro hernia system.

spermatic cord, and separation of the hernia sac from the cord contents and the sac is then, transfixed ligated at its proper neck.

At this stage, the inferior epigastric vessels are identified and lifted at right angle by 2 Langenbeck retractors by the assistant surgeon. On lifting the inferior epigastric vessels, the pre-peritoneal space can be approached and dissected away from the fascia transversalis by both blunt dissection and inserting swabs. In case of direct hernia, the hernia sac should be carefully reduced from inside and separated from the fascia transversalis. The dissection is continued to open a capacious space accommodating the inlay patch (Figure 2(a)).

The dissection extends infer-medially to Cooper's ligament to ensure complete coverage of the myo-pectineal orifice. The iliac vessels are protected in the lateral part of the dissection. The inlay patch is then applied in this pre-peritoneal space. If the dissection is adequate, the oval patch of UHS (its inlay patch measures $12 \times 8 \mathrm{~cm}$ ) should be spread easily as medial as possible to cover the whole myo-pectineal orifice (Figure $2(\mathrm{~b})$ ). The connector is passed through the deep ring and the onlay patch is then placed over the fascia transversalis with a slit made in it to pass the spermatic cord (Figure 2(c)).

The only patch is fixed by 3 Vicryl $3 / 0$ stitches: first one in its medial end close to the pubic bone with at least $1 \mathrm{~cm}$ of overlap, second one to fix it to the conjoint tendon at the level of the deep ring to prevent mesh rotation, and the third one fixing the slit to the inguinal ligament. The inguinal wound is then closed in layers by Vicryl 2/0 and the skin is closed by Monocryl 3/0 in a subcuticular fashion.

All the patients resumed oral intake 4 hours after the surgery, received Pethidine $50 \mathrm{mg}$ intramuscular every 6 hours. They were discharged home on the next day with oral Ibuprofen $400 \mathrm{mg}$ twice daily.

All the patients were seen in the out-patient clinic after 1 week, 1 month, 3 months of surgery and then each 6 months for 2 years.

\section{Results}

The age of the patients ranged between 23 and 81 years with mean of 46.1 years (Table 1). Thirty three patients presented with inguino-scrotal hernias, 14 hernias were classified as Nyhus type IIIA, 22 were Nyhus type IIIB, \& 6 patients were presented by strangulated hernias (Table 2). Operative time ranged between 35 and 88 minutes with a mean of 48 minutes. 


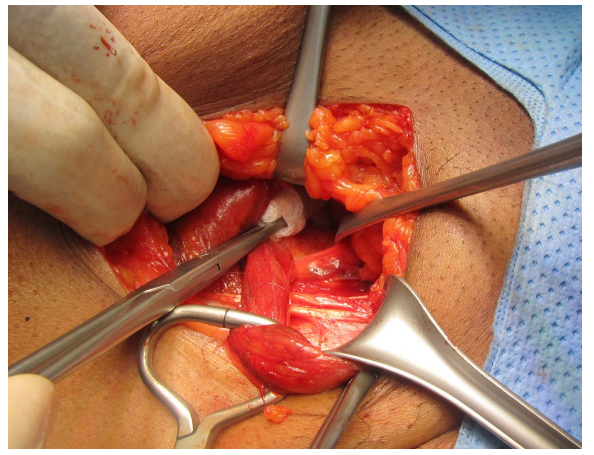

(a)

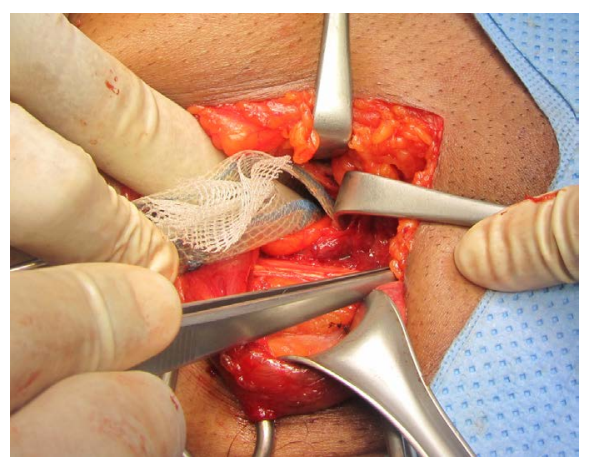

(b)

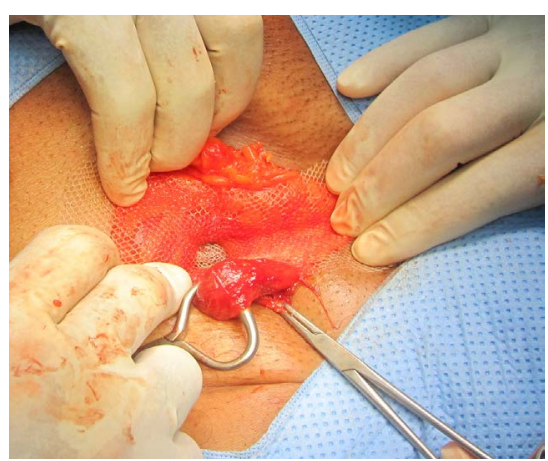

(c)

Figure 2. (a) Dissection of the pre-peritoneal space; (b) The inlay patch is applied in the pre-peritoneal space; (c) A slit in the onlay patch for the cord and spreading over the fascia transversalis.

Table 1. Patients' demographics.

\begin{tabular}{cc}
\hline Patients' Demographic & No. (\%) \\
\hline Sex: & $75(100)$ \\
Male & $0(0)$ \\
Female & \\
Age: & $36(48)$ \\
Less than 40 & $27(36)$ \\
$40-60$ & $11(14.7)$ \\
$60-80$ & $1(1.3)$ \\
More than 80 & \\
\hline
\end{tabular}

Table 2. Classification of hernias included in the study.

\begin{tabular}{cc}
\hline Type of Hernia & No. (\%) \\
\hline Inguino-scrotal & $33(44)$ \\
Nyhus type IIIA & $14(18.7)$ \\
Nyhus type IIIB & $22(29.3)$ \\
Strangulated & $6(8)$ \\
\hline
\end{tabular}


No operative complications were recorded in any of the patients.

Post-operatively, the mean VAS scale on 1 day, 1 week, \& 1 month was 3.22, $1.2, \& 0.3$ respectively. The mean duration of oral analgesics use post-operatively was 2.1 days (Table 3). None of the patients reported any chronic pain at 12 months after the surgery.

Two cases of superficial wound infection were recorded that were treated by oral antibiotics with no surgical drainage needed.

No recurrence was reported during the follow up period that ranged between 36 and 10 months with a mean of 26 months (Table 4).

\section{Discussion}

Surgeons are still looking for the ideal mesh to use in inguinal hernia repair. It should be cost effective, covering the myo-pectineal orifice completely, with minimal post-operative complications. It should give the patient the minimal post-operative pain, less chronic groin pain, and allows for the rapid resumption of the usual daily activities. It should have the minimal possible recurrence rate [9].

In Lichtenstein repair, the mesh is placed anteriorly to reinforce the muscle shutter mechanism. On the other hand, in the pre-peritoneal approach, the mesh is placed posteriorly in the pre-peritoneal space to cover Fruchaud myo-pectineal orifice completely [10] [11]. In 1997, Gilbert described his technique [4] that combined both the anterior and the posterior pre-peritoneal approach by the use of the Prolene Hernia System that gives the patient the advantages of both techniques with comparable short and long term results [12].

The mechanism of post-operative chronic pain after inguinal hernia repair using meshes is not yet fully understood. However, many factors have been considered e.g. remaining mesh size \& weight, fixation material, excessive scarring and nerve injuries or entrapment by sutures [13] [14].

Table 3. Surgical outcomes.

\begin{tabular}{cc}
\hline Operative results & Mean \pm SD \\
\hline $\begin{array}{c}\text { Operative time } \\
\text { Post-operative Results: } \\
\text { VAS Scale: }\end{array}$ & $48 \pm 20.4$ \\
1 day & $3.22 \pm 1.3$ \\
1 week & $1.2 \pm 0.4$ \\
1 month & $0.3 \pm 0.11$ \\
Duration of oral analgesic use (days) & $2.1 \pm 0.9$ \\
\hline
\end{tabular}

Table 4. Post-operative complications.

\begin{tabular}{cc}
\hline Complication & No. (\%) \\
\hline Superficial wound infection & $2(0.027)$ \\
Recurrence & $0(0)$ \\
\hline
\end{tabular}


In attempts of reducing chronic pain, more interest has been recently focused on the mesh material. The introduction of the light weight meshes was found to be associated with less chronic pain, less patient's discomfort, and better quality of life after mesh repair of inguinal hernia with no difference in recurrence rate if compared to the classic heavy weight prolene mesh [8] [15] [16] [17]. Light weight mesh has large pore size that allows rapid tissue ingrowth. It allows minimizing tissue exposure to mesh by reducing the weight and surface area that optimize the foreign body reaction and leaves less permanent mass [18] [19]. Ultra-Pro Hernia system is a light weight mesh that provides the patient with all the advantages of this new generation of meshes. It allows for complete coverage of the myo-pectineal orifice by the inlay patch. The onlay patch covers the floor of the inguinal canal with pubic tubercle overlapping, and the connector works as a plug for the deep ring and stabilizes the inlay patch preventing its migration [18]. Moreover, UHS devise is fixed by only 3 absorbable stitches which is another important factor in reducing foreign body and decreasing post-operative pain, chronic groin discomfort, and foreign body sensation.

The current study assessed the efficacy of UHS in inguinal hernia repair. The mean operative time was 48 minutes, no operative complications was reported. Only 2 superficial wound infections were seen and treated medically without surgical intervention. The post-operative pain was minimal and none of the patients reported any chronic groin pain after 12 months of surgery. No recurrence was encountered during a mean follow up period of 26 months. These results are comparable to results of many other studies [20] [21]. When comparing UHS with the classic Lichtenstein repair of inguinal hernia, many studies showed equivalent results for both techniques regarding intra and post-operative complications, length of hospital stay, duration of analgesics use, and time to return to usual activities [10] [11] [22]. Regarding operative time, some studies showed shorter operative time for UHS [20] [23]; other studies had longer operative time for UHS compared to Lichtenstein repair [24].

However, we think that UHS inguinal hernia repair is not without limitations. The cost of UHS is high if compared to classic meshes. The UHS application needs proper dissection of the pre-peritoneal space which may be difficult technically specially in the beginning of the learning curve. Nevertheless, the learning curve does not take long time. Finally, it makes the feasibility of the laparoscopic repair in future very difficult if recurrence develops [22]. Moreover, the study should be extended to include other types of inguinal hernia e.g. recurrent hernia and inguinal hernia in females.

\section{Conclusion}

In conclusion, UHS inguinal hernia repair is an effective technique that combines the advantages of the anterior and the pre-peritoneal approaches. It improves the patient quality of life with less chronic groin pain and minimal recurrence rates. However, a larger number of patients with longer follow-up periods are needed to make our results more valid and strong. 


\section{References}

[1] Simons, M.P., Aufenacker, T., Bay-Nielsen, M., et al. (2009) European Hernia Society Guidelines on the Treatment of Inguinal Hernia in Adult Patients. Hernia, 13, 343-403. https://doi.org/10.1007/s10029-009-0529-7

[2] Nyhus, L.M. (1993) Ilio-Pubic Tract Repair of Inguinal and Femoral Hernia: The Posterior (Pre-Peritoneal) Approach. Surgical Clinics of North America, 73, 487499. https://doi.org/10.1016/S0039-6109(16)46032-9

[3] Rignault, D.P. (1986) Pre-Peritoneal Prosthetic Inguinal Hernioplasty through a Pfannenstiel Approach. Surgery, Gynecology \& Obstetrics, 163, 465-468.

[4] Gilbert, A.I. and Graham, M.F. (1997) Symposium on the Management of Inguinal Hernias. Sutureless technique: Second Version. Canadian Journal of Surgery, 40, 209-212.

[5] O’Dwyer, P.J., Kingsnorth, A.N., Molloy, R.G., et al. (2005) Randomized Clinical Trial Assessing Impact of a Light Weight or Heavy Weight Mesh on Chronic Pain after Inguinal Hernia Repair. British Journal of Surgery, 92, 166-170. https://doi.org/10.1002/bjs.4833

[6] Bringman, S., Wollert, S., Osterberg, J., et al. (2006) Three-Year Results of a Randomized Clinical Trial of Light Weight or Standard Polypropylene Mesh in Lichtenstein Repair of Primary Inguinal Hernia. British Journal of Surgery, 93, 10561059. https://doi.org/10.1002/bjs.5403

[7] Nyhus, L.M. (1993) Individualization of Hernia Repair: A New Era. Surgery, 114, $1-2$.

[8] Ruiz-Jabson, F., Ticehurst, K., Norrby, J., et al. (2015) Topic: Inguinal HerniaCrossfire between the Meshes. Hernia, 19, S251-S253.

https://doi.org/10.1007/BF03355365

[9] Awad, S.S. and Fagan, S.P. (2004) Current Approaches to Inguinal Hernia Repair. The American Journal of Surgery, 188, 9S-16S. https://doi.org/10.1016/j.amjsurg.2004.09.007

[10] The European Hernia Trialists Collaboration (2002) Repair of Groin Hernia with Synthetic Mesh: Meta-Analysis of Randomized Controlled Trials. Annals of Surgery, 235, 322-332. https://doi.org/10.1097/00000658-200203000-00003

[11] Muldoon, R.L., Marchant, K., Johnson, D.D., et al. (2004) Lichtenstein vs Anterior Pre-Peritoneal Prosthetic Mesh Placement in Open Inguinal Hernia Repair: A Prospective Randomized Trial. Hernia, 8, 98-103. https://doi.org/10.1007/s10029-003-0174-5

[12] Sanjay, P., Watt, D.G., Ogston, S.A., et al. (2012) Meta-Analysis of Prolene Hernia System Mesh versus Lichtenstein Mesh in Open Inguinal Hernia Repair. The Surgeon, 10, 283-289.

[13] Heise, C.P. and Starling, J.R. (1998) Mesh Inguinodynia: A New Clinical Syndrome after Inguinal Hernioplasty? Journal of the American College of Surgeons, 187, 514518. https://doi.org/10.1016/S1072-7515(98)00215-4

[14] Di Vita, G.M.S. and Frazetta, M. (2000) Tension-Free Hernia Repair Is Associated with an Increase in Inflammatory Response Markers against the Mesh. The American Journal of Surgery, 180, 203-207. https://doi.org/10.1016/S0002-9610(00)00445-1

[15] Klosterhalfen, B., Junge, K. and Klinge, U. (2005) The Light Weight and Large Porous Mesh Concept for Hernia Repair. Expert Review of Medical Devices, 2, 103-117. https://doi.org/10.1586/17434440.2.1.103

[16] Bittner, R., Schmedt, C.G. and Leibl, B.J. (2011) Early Postoperative and One Year 
Results of a Randomized Controlled Trial Comparing the Impact of Extra light Titanized Polypropylene Mesh and Traditional Heavyweight Polypropylene Mesh on Pain and Seroma Production in Laparoscopic Hernia Repair (TAPP). World Journal of Surgery, 35, 1791-1797. https://doi.org/10.1007/s00268-011-1148-X

[17] Horstmannn, R., Hellwig, M., Classen, C., et al. (2006) Impact of Polypropylene Amount on Functional Outcome and Quality of Life after Inguinal Hernia Repair by the TAPP Procedure Using Pure, Mixed, and Titanium-Coated Meshes. World Journal of Surgery, 30, 1742-1749. https://doi.org/10.1007/s00268-005-0242-3

[18] Tollens, T., Devroe, K., Speybrouck, S., et al. (2011) UltraPro Hernia System: Toward an Ideal Solution? The Bonheiden Experience with a Partially Absorbable and Macroporous Bilayer Device. Surgical Technology International, 21, 128-134.

[19] Cobb, W., Kerchner, W. and Heniford, T. (2005) The Argument of Light Weight Polypropylene Mesh in Hernia Repair. Surgical Innovation, 12, 63-69.

https://doi.org/10.1177/155335060501200109

[20] Dalenback, J., Andersson, C., Anesten, B., et al. (2009) Prolene Hernia System, Lichtenstein Mesh and Plug-and-Patch for Primary Inguinal Hernia Repair: 3-Year Outcome of a Prospective Randomized Controlled Trial. The BOOP Study: Bi-Layer and Connector, On-Lay, and On-Lay with Plug for Inguinal Hernia Repair. Hernia, 13, 121-129. https://doi.org/10.1007/s10029-008-0443-4

[21] Zhao, G., Gao, P., Ma, P., et al. (2009) Open Mesh Techniques for Inguinal Hernia Repair: A Meta-Analysis of Randomized Controlled Trials. Annals of Surgery, 250, 35-42. https://doi.org/10.1097/SLA.0b013e3181ad63cc

[22] Magnusson, J., Nygren, J. and Thorell, A. (2012) Lichtenstein, Prolene Hernia System, and Ultrapro Hernia System for Primary Inguinal Hernia Repair: One-Year Outcome of a Prospective Randomized Controlled Trial. Hernia, 16, 277-285. https://doi.org/10.1007/s10029-012-0903-8

[23] Kingsnorth, A.N., Wright, D., Porter, C.S. and Robertson, G. (2002) Prolene Hernia System Compared with Lichtenstein Patch: A Randomized Double Blind Study of Short-Term and Medium-Term Outcomes in Primary Inguinal Hernia Repair. Hernia, 6, 113-119. https://doi.org/10.1007/s10029-002-0066-0

[24] Karateke, F., Ozyazici, S., Menekse, E., et al. (2014) Ultrapro Hernia System versus Lichtenstein Repair in Treatment of Primary Inguinal Hernias: A Prospective Randomized Controlled Study. International Surgery, 99, 391-397.

https://doi.org/10.9738/INTSURG-D-14-00064.1

\section{Submit or recommend next manuscript to SCIRP and we will provide best service for you:}

Accepting pre-submission inquiries through Email, Facebook, LinkedIn, Twitter, etc. A wide selection of journals (inclusive of 9 subjects, more than 200 journals)

Providing 24-hour high-quality service

User-friendly online submission system

Fair and swift peer-review system

Efficient typesetting and proofreading procedure

Display of the result of downloads and visits, as well as the number of cited articles

Maximum dissemination of your research work

Submit your manuscript at: http://papersubmission.scirp.org/

Or contact ss@scirp.org 